\title{
Há Lugar para o Poder Constituinte no Mundo Moderno?
}

\author{
Sidnei ONachado
}

Advogado, Mestre em Direito das Relações Sociais e Doutorando pela UFPR.

"Toda sociedade, em que a garantia dos direitos não é assegurada, nem a separação de poderes determinada, não tem Constituição." (art. 16 da Declaração dos Direitos do Homem e do Cidadão de 1789)

\section{SUMÁRIO}

1 As alternativas dentro do projeto da modernidade;

2 Limites do poder de revisão: um ponto de partida;

3 Algumas considerações finais;

Bibliografia.

\section{As alternativas dentro do projeto da modernidade}

A

problemática do poder constituinte no mundo moderno põe em evidência a ampla e cara reflexão sobre os dilemas do projeto da modernidade iluminista. Os pressupostos dessa leitura decorriam da implosão dos postulados fundadores desse projeto: a crise da razão iluminista, com os vários desdobramentos no modo de produção capitalista e nas várias esferas do mundo da vida. $O$ poder constituinte, ao comer o fruto proibido da árvore da modernidade, agora agonizaria e reviveria vários de seus paradoxos históricos. Vários, então, poderiam ser os pontos de partida para enfrentar essa temática, mas pretendemos fazer um recorte para localizar no direito e no direito constitucional, numa perspectiva meramente compreensiva, os caminhos possíveis para um repensar ou um reafirmar, em outros postulados, o legado do poder constituinte dentro da utopia do projeto da modernidade.

A idéia de uma Constituição escrita, nos moldes preconizados pelo contra- 
tualismo, é que colocou a categoria do poder constituinte no centro do debate político. Sim, uma constituição, mas escrita por quem? Inicia-se assim a chamada problemática do poder constituinte, como um dos temas mais relevantes do constitucionalismo moderno. CANOTILHO esclarece que essa problemática decorre da complexa aproximação entre temas de teoria política, da filosofia, da ciência política, da teoria da constituição e do constitucionalismo. E, indica que essa problemática decorre de 4 (quatro) questões: a) $\bigcirc$ que é o poder constituinte? b) Quem é o titular desse poder? c) Qual o procedimento e a forma do seu exercício? d) Existem ou não limites jurídicos e políticos quanto ao exercício desse poder? ${ }^{1}$

Como o poder constituinte é antes de tudo um problema de legitimidade, o seu questionamento perpassa o debate que acompanha todo o Estado Democrático e de Direito. Historicamente, o poder constituinte teve que se justificar enquanto fundamento jurídico e político. $\bigcirc$ tema, portanto, não é novo. A origem do poder constituinte e a sua limitação no processo de revisão, sempre na perspectiva da legitimidade, sem dúvida são as questões mais recorrentes que permearam a problemática.

Qual a origem do poder constituinte? Não há uma explicação racional que dê conta dessa indagação. Qualquer resposta redundará sempre no mesmo enunciado tautológico: no princípio era o poder cons- tituinte. Usando de uma metáfora e de refinada ironia, CLAUDE KLEIN diz que a sua origem é uma lenda, um conto de fadas para crianças, uma crença cristã. ${ }^{2}$ Enfim, estaríamos diante de uma "magia racionalizada" ou "de uma ideologia moderna e racional do poder constituinte". ${ }^{3}$ Não tem então o poder constituinte um fundamento jurídico, pois representa apenas o poder de editar a constituição. $\bigcirc$ decisionismo schmittiano pode se inserir nesse mesmo conceito, pois reconhece que, considerada do ponto de vista normativo, a decisão nasce do nada.

No entanto, para desfazer o dilema do político e do jurídico no poder constituinte, é importante lembrar que $\mathrm{BOBBIO}$, ao discorrer sobre a crise do estado soberano, recorre às expressões "figuração" e "realidade", para afirmar que: "O que assegura a unidade do todo é a lei, e quem tem o poder de fazer as leis é o soberano. Tratase porém de uma figuração. A realidade da vida política é bem diferente. A realidade da vida política se desenvolve através de conflitos jamais resolvidos em definitivo, e cuja resolução acontece mediante acordos momentâneos, tréguas e esses tratados de paz mais duradouros que são as constituições”. E mais adiante conclui BOBBIO: "Este contraste entre figuração e realidade pode ser bem exemplificado pela não-coincidência entre a ininterrupta continuidade do conflito secular, típico da idade moderna (...) a doutrina do estado, baseada sobre

1 CANOTILHO, José Joaquim Gomes. Direito constitucional, p. 59.

2 KLEIN, Claude. Théorie et pratique du pouvoir constituant. Paris: Presses Universitaires de France, 1996, p. 204.

3 Idem, p. 196. 
o conceito de soberania, de unidade de poder, de primado do poder legislativo (....)". ${ }^{4}$ Poderíamos compreender então o poder constituinte como uma espécie de figuração e que, portanto, não está sujeito à racionalização.

problema é que a constatação da ausência de racionalização representa, de início, um balde de água fria no projeto de constituição, pois esta deve ser entendida também como uma obra do racionalismo com vistas à emancipação humana. Se não bastassem essas questões irrespondíveis, muito próximo do dilema da crítica da razão prática kantiana (onde a razão é negada por obra da própria razão humana), ao poder constituinte é cobrado hoje também uma fundamentação de legitimidade procedimental numa sociedade denominada hipercomplexa. A questão posta é como o poder constituinte, no seu projeto universalizante, que busca legitimidade democrática, pode dar conta de congregar as várias racionalidades em jogo em uma sociedade fragmentária? No plano filosófico, como justificar o discurso do poder constituinte, sem uma grande narrativa universal? Como pode o poder constituinte estabelecer novos compromissos, racionalizar um poder multifacetado da modernização capitalista globalizante, que rompeu com os limites de regulação do estado-nação?

Este duro relato da trajetória do poder constituinte (e do projeto da constituição) nos dá uma real sensação de que temos poucas alternativas dentro da moldura do projeto da modernidade. Mas o processo político é dialético, desembocando sempre numa síntese. Estamos entre aqueles que reputam que o poder constituinte se insere efetivamente nas esferas da filosofia e da política, razão pela qual não comporta uma racionalização definitiva, sendo inevitáveis as tensões. BOAVENTURA DE SOUZA SANTOS, trabalhando numa perspectiva utópica (utopia do possível), reputa que: "As exigências práticas da regulação estão, assim, subordinadas à experiência racional, que, por sua vez, longe de ser um produto técnico com fins instrumentais, constitui a procura por uma nova ética política e social ajustada aos novos tempos e aos novos ideais de autonomia e liberdade". ${ }^{5}$

Essa abertura compreensiva do direito proposta por BOAVENTURA pode representar uma ameaça, mas também uma oportunidade. Reflexões importantes avançam na direção do resgate da modernidade inacabada, apontando para um resgate ético do direito e dos valores da comunidade. ${ }^{6}$ Contudo, não vemos outra alternativa que não passe pelo Estado (como lugar ideal ético, no sentido hegeliano), pelo aprimoramento da democracia como sistema político e o direito como utopia, ideologia e discurso. Diante de tudo isso, o que nos resta é fazer a defesa das regras do jogo: o poder constituinte. Subsistirão certamente ao poder constituinte ainda as questões atinentes ao paradoxo da democracia.

4 BOBBIO, Norberto. O futuro da democracia, p. 132.

5 SANTOS, Boaventura de Sousa. A crítica da razão indolente, p. 123.

6 Pensamos em HABERMAS com a sua teoria do discurso; BOAVENTURADE SOUZA SANTOS com o seu re-pensar do direito e da ciência; ENRIQUE DUSSEL com referencial teórico da Ética da Libertação, dentre outros. 


\section{Limites do poder de revisão: um ponto de partida}

Se é fato que o poder constituinte (dito originário) não é uma categoria jurídica, restam aos juristas as questões relacionadas aos limites do poder de revisão. Talvez nunca os juristas tenham sido convocados a opinar sobre a "validade", a "legalidade" ou a "legitimidade" como vivenciamos no último quartel do século XX. A razão decorre dos sopros das mudanças no eixo central do modelo de Estado, com forte tendência à redução de seu papel. Como na cena final do filme "O advogado do diabo", a escolha da arena do direito não se dá por acaso, mas na feliz síntese do personagem do advogado: o direito é tudo. Cabe ao direito, assim, dizer quais os limites que o poder de revisão (poder político) pode empreender nessa saga.

A primeira tese que apresentamos é que há lugar para o poder constituinte de revisão (derivado). Se este, de forma cotidiana nas democracias constitucionais, em especial por via de suas cortes constitucionais, tem sido invocado a se pronunciar sobre a validade da revisão de determinada norma constitucional, estaríamos a confirmar a sua importância e seu papel central no cenário político e jurídico.

É claro que entre o poder constituinte originário e o reclamo e a vocação para mudanças há sempre uma tensão. Porém, a questão dos limites do poder de revisão está relacionada à problemática do conteúdo e da legitimidade de uma Constituição e aos limites do poder constituinte. Daí decorre a seguinte indagação: há efetivamente uma reserva na Constituição de normas e princípios (um núcleo duro) que não se sujeita a revisões e a alterações?

A imutabilidade das cláusulas pétreas é ainda controvertida na teoria e na jurisprudência constitucional. Se entendida que elas representam proibição de ruptura de determinados princípios constitucionais, logo é de se admitir que seu significado é bem mais amplo, abrangendo também aquelas alterações tópicas que possam acarretar a erosão da própria constituição. Para GILMAR FERREIRA MENDES, “teoricamente os limites do poder de revisão não se restringem, necessariamente, aos casos expressamente elencados nas garantias de eternidade"?

CLAUDE KLEIN bem demonstrou como a prática da jurisprudência constitucional nos diversos países de tradição democrática revelou quanto são contraditórios, por vezes ineficazes, os mecanismos de controle material positivados ou supraconstitucionais. ${ }^{8}$ A jurisprudência constitui-se num discurso, com uma marcada inferência ideológica.

A história recente do caso brasileiro é exemplar para evidenciar essa trajetória do poder constituinte de revisão, onde teoria e prática andam divorciadas. Essa postura em geral tem sido justificada por um pragmatismo (uma espécie de ética da res-

7 MENDES, Gilmar Ferreira. Direitos fundamentais e controle de constitucionalidade, p. 124.

8 Ver Théorie et pratique du pouvoir constituant, Paris: Presses Universitaires de France, 1996. 
ponsabilidade weberiana). GILMAR FERREIRA MENDES esclarece que da perspectiva teórica é correta a proibição de ruptura de determinados princípios constitucionais. Mas seria inconseqüente, pois ao invés de assegurar a continuidade do sistema constitucional, isso "pode antecipar a sua ruptura permitindo que o desenvolvimento constitucional se realize fora de eventual camisa de força do regime da imutabilidade". ${ }^{9}$ E conclui GILMAR como sendo esse o grande desafio da jurisdição constitucional, qual seja: "não permitir a eliminação do núcleo essencial da Constituição, mediante decisão ou gradual processo de erosão, nem ensejar que uma interpretação ortodoxa acabe por colocar a ruptura como alternativa à impossibilidade de um desenvolvimento constitucional legítimo".

A posição do STF é de que a Emenda da constitucional deve se submeter ao controle da constitucionalidade. Sob a égide da Constituição de 1988, ao apreciar a Emenda no 2, de 1992, o STF (ADIn 829 e 830) asseverou que o Poder Legislativo não exorbitou de suas competências. Também sobre a emenda do IPMF, entendeu o STF que a cobrança no mesmo exercício violava o princípio da anterioridade, reconhecendo ainda a incompatibilidade do referido tributo com o princípio federativo da imunidade recíproca. $\bigcirc$ fundamento que balizou o voto proferido pelo Ministro MOREIRA ALVES é de que é preciso "bus- car uma posição de equilíbrio que não conduza ao extremo da máxima redução do significado das cláusulas pétreas nem que leve ao extremo oposto da imobilização do sistema constitucional". Lembrou, ainda, com base na posição da Corte Alemã, que as "garantias de eternidade são excepcionais, não devem elas ser interpretadas de modo a impedir que o legislador constituinte introduza modificações que sejam imanentes ao sistema jurídico". ${ }^{10}$

A questão prática não solucionada é de como assegurar uma posição de equilíbrio que compatibilize a proteção do núcleo da constituição e ao mesmo tempo permita o desenvolvimento constitucional? Além das limitações materiais expressas, que já fazem parte de um grande número de Constituições (as quais não se pode negar eficácia), sem dúvida ainda subsiste a importância da teoria da fraude à constituição, como limitações inerentes à Constituição. Conquanto controversas até hoje na doutrina (teoricamente reconhecido como tema complexo), o reconhecimento dos princípios supraconstitucionais revela o grau de controle exercido pelas cortes constitucionais.

É verdade que uma Constituição não se resume a um amontoado de normas de distribuição de competências, ao contrário, ela repousa sobre certos princípios sem os quais ela perde a sua razão de ser. Claro que é preferível introduzir na Constituição disposições específicas de intangibilidade, mas

9 MENDES, Gilmar Ferreira. Direitos fundamentais e controle de constitucionalidade, p. 125.

10 Idem, p. 126. Por essa razão GILMAR entende que 0 $\S 4^{\circ}$ do art. 60 da Constituição brasileira, ao mencionar a proibição de emendas "tendentes a abolir", para GILMAR não se trata de imutabilidade absoluta, dado que devem ser interpretadas de forma restritiva. 
ainda permanece válido o recurso à expres são "fraude à Constituição".

\section{Algumas considerações finais}

Se é verdade que o projeto da modernidade subsiste (mesmo porque ainda não cumprido), há espaços de luta dentro desse projeto. $O$ poder constituinte no mundo moderno, conquanto esvaziado, como lugar da utopia, do possível, deve servir como resistência ao niilismo irracionalista que tem se propagado em certas posturas pós-modernas. A questão é colocar o poder constituinte em outros termos e pressupostos, tarefa esta ainda em construção.

No plano da teoria da constituição, podemos compreender que, se para uma Constituição não se deseja que seja a imutabilidade, talvez devêssemos reclamar certa estabilidade nas mudanças, a fim de evitar um esvaziamento ou mesmo o rompimento com a estrutura da Constituição.

No Estado Democrático de Direito a questão da revisão constitucional não pode ser justificada meramente por uma adequação da realidade jurídica à realidade política, em prejuízo de uma normatividade constitucional. Mas como frisou NORBERTO BOBBIO, em o Futuro da Democracia, as constituições são feitas pelas forças políticas, que as fazem e refazem; mas o direito é feito pelos juízes.
Por fim, impossível não aproximar todas essas questões à história recente das emendas à Constituição brasileira. $\bigcirc$ processo de reformas sofridas pela Constituição de 1988, tendo o Presidente da República atuado como uma espécie de "relator", pode estar maculado pela "fraude à Constituição", pois pode-se desdenhar a perda do verdadeiro "espírito da Constituição".

\section{Bibliografia}

AGRA, Walber de Moura. Fraudes à Constituição: um atentado ao poder reformador. Porto Alegre: Sérgio Fabris Editor, 2000.

BOBBIO, Norberto. O futuro da democracia. 5. ed., São Paulo: Paz e Terra, 1992.

BRITO, Edvaldo. Limites da revisão constitucional. Porto Alegre: Sérgio Fabris Editor, 1993.

CANOTILHO, José Joaquim Gomes. Direito constitucional. 6. ed., Coimbra: Almedina, 1997.

CUNHA, Paulo Ferreira da. Constituição, direito e utopia. Do jurídico-constitucional nas utopias politicas. Coimbra Editora, 1996.

DUSSEL, Enrique. Ética da libertação. São Paulo: Vozes, 2000.

HABERMAS, Jürgen. Direito e democracia. Entre facticidade e validade. Vol. I e II, São Paulo: Tempo Brasileiro, 1997.

MENDES, Gilmar Ferreira. Direitos fundamentais e controle de constitucionalidade. São Paulo: Celso Bastos Editor, 1998.

KLEIN, Claude. Théorie et pratique du pouvoir constituant. Paris: Presses Universitaires de France, 1996.

SANTOS, Boaventura de Souza. A crítica da razão indolente. Vol. 1, São Paulo: Cortez, 2000. . A crítica da razão indolente. Para umnovo senso comum. Vol. 1, São Paulo: Cortez, 2000.

SCHMITT, Carl. Théorie de la constituition. Paris: PUF, 1989. 